Article

\title{
On the Representativeness of UTOPIA Land Surface Model for Creating a Database of Surface Layer, Vegetation and Soil Variables in Piedmont Vineyards, Italy
}

\author{
Claudio Cassardo 1,2,*(D) and Valentina Andreoli ${ }^{3}$ \\ 1 Department of Physics and NatRisk Centre, University of Torino “Alma Universitas Taurinorum”, \\ 10125 Torino, Italy \\ 2 Department of Environmental Science \& Engineering and Center for Climate/Environment Change \\ Prediction Research (CCCPR), Ewha Womans University, Seoul 03760, Korea \\ 3 Department of Physics, University of Torino "Alma Universitas Taurinorum", 10125 Torino, Italy; \\ valentina.andreoli@unito.it \\ * Correspondence: claudio.cassardo@unito.it; Tel.: +39-011-670-7407
}

Received: 1 July 2019; Accepted: 6 September 2019; Published: 16 September 2019

\begin{abstract}
The main aim of the paper is to show how, and how many, simulations carried out using the Land Surface Model UTOPIA (University of TOrino model of land Process Interaction with Atmosphere) are representative of the micro-meteorological conditions and exchange processes at the atmosphere/biosphere interface, with a particular focus on heat and hydrologic transfers, over an area of the Piemonte (Piedmont) region, NW Italy, which is characterized by the presence of many vineyards. Another equally important aim is to understand how much the quality of the simulation outputs was influenced by the input data, whose measurements are often unavailable for long periods over country areas at an hourly basis. Three types of forcing data were used: observations from an experimental campaign carried out during the 2008, 2009, and 2010 vegetative seasons in three vineyards, and values extracted from the freely available Global Land Data Assimilation System (GLDAS, versions 2.0 and 2.1). Since GLDAS also contains the outputs of the simulations performed using the Land Surface Model NOAH, an additional intercomparison between the two models, UTOPIA and NOAH, both driven by the same GLDAS datasets, was performed. The intercomparisons were performed on the following micro-meteorological variables: net radiation, sensible and latent turbulent heat fluxes, and temperature and humidity of soil. The results of this study indicate that the methodology of employing land surface models driven by a gridded database to evaluate variables of micro-meteorological and agronomic interest in the absence of observations is suitable and gives satisfactory results, with uncertainties comparable to measurement errors, thus, allowing us to also evaluate some time trends. The comparison between GLDAS2.0 and GLDAS2.1 indicates that the latter generally produces simulation outputs more similar to the observations than the former, using both UTOPIA and NOAH models.
\end{abstract}

Keywords: land-surface; UTOPIA; NOAH; GLDAS; micrometeorology; exchanges processes; vineyards

\section{Introduction}

Numerical models and, in particular, models including soil-vegetation-atmosphere transfer schemes (hereafter referenced to as "land surface models", or LSMs), can be considered useful tools to estimate microclimatic conditions in specific sites. These kinds of models can simulate hydro-energetic and gas exchange processes in the layer including atmosphere, soil, and vegetation. Recent studies 
demonstrate that the accuracy of land surface processes diagnosed by land surface models can be further improved by considering specific aspects of vegetation growth, such as vegetation structure parameterizations [1] and LAI (Leaf Area Index) seasonality [2].

Environmental conditions, especially microclimatic conditions, strongly influence agricultural production. For this reason, there is an increasing interest in assessing plant responses to environmental variables, especially in periods characterized by climatic changes, as the actual one [3].

Grapevine is a robust plant, but it is extremely sensitive to environmental conditions, and the characterization of its microphysics variability, in functions of field-dependent factors and external weather conditions, is useful to understand its growth process [4].

The interest in grapevine is increasing, which is also due to the great economic weight of its product: the wine [5]. This is particularly true for the areas in which famous wines are produced, such as the Italian region Piemonte (Piedmont), with its Barolo and Barbaresco (among others) world-renowned wines. For this reason, many studies were conducted to evidence the relationships between physical variables (temperature, radiation, soil water content) and plant development [6-10]. It is also evident that, conversely, management practices can influence the microclimate within a vineyard [11,12]. For this reason, the employment of an instrument, such as a LSM, can drive grower decisions for decreasing the environmental impact of vineyard management $[13,14]$. Vineyards can thus be seen as a complex system where many variables interact between themselves to determine the plant growth, and ultimately the quantity and quality of grapevine production.

A tool able to estimate plant responses to environment at the microscale is represented by numerical models, and more specifically LSMs and crop growth models [15-17]. In particular, LSMs evolved over time from a very simple approach (first generation models), representing simplified surface energy and hydrological balances (for instance, [18]) to the second generation models [19-21], in which the surface was interacting with the atmosphere and the presence of vegetation was explicitly represented in the exchange processes, and then to the third generation models, that further improved the simulation of the evapotranspiration pathway and considered the plant carbon uptake by means of an explicit canopy conductance (among others, the UTOPIA-University of Torino model of land Process Interaction with Atmosphere [22] - used in this work and described in the section "Material and methods"). LSMs and crop models (such as STICS - Simulateur mulTIdisciplinaire pour les Cultures Standard $[15,16]$ and IVINE - Italian Vineyard Integrated Numerical model for Estimating physiological values [23]) can help the winemakers in supporting their decision system [24]. Eventually, LSMs can also include eco-physiological modules able to simulate variables related to vegetation growth, expressly optimized for different kinds of vegetation, as it is the case of the UTOPIA.

In this context, the land surface becomes a key driver of the hydrological cycle and is fundamental to the overall functioning of the atmospheric and climate processes [25]. It is the surface layer that controls the partitioning of the available energy, between sensible and latent heat fluxes, and surface water, between evaporation, runoff, precipitation, and soil storage. It is also the location in which the carbon is stored or emitted, as the result of the processes of photosynthesis and respiration. Because the accurate knowledge of these processes is important for weather and climate predictions, most numerical weather predictions centers incorporated simplified LSMs in their models, as internal routines.

The purpose of the complete study of our group, included in the frame of the MACSUR2 project (the second phase of the project MACSUR-Modelling European Agriculture with Climate Change on Food Security, whose full proposal is available here (MACSUR phase 1: https://macsur.eu/images/ download/fullproposal.pdf. MACSUR phase 2: https://macsur.eu/images/download/MACSUR2\% 20Proposal.pdf)), is to understand the effects of climate change on a specific kind of vegetation: the vineyards. This goal was pursued using a crop model [23] whose input consisted of hourly or sub-hourly parameters, derived in part from GLDAS (Global Land Data Assimilation System) and in part from the simulations performed with the UTOPIA (we needed to run a LSM as the data included in GLDAS were insufficient to drive the crop model). This paper concerns the first part of the study, 
e.g., the simulation of the components of hydrological and energy budgets, and soil variables using a LSM. There were three scientific questions of this study:

- to determine if, and to what extent, the simulations carried out using the Land Surface Model UTOPIA were representative of the micro-meteorological conditions and exchange processes at the atmosphere/biosphere interface over an area in Piemonte region planted with vineyards;

- to understand how much the simulation outputs were influenced by the quality of the input data;

- to intercompare the two LSM UTOPIA and NOAH, driven by the same datasets, in order to find eventual deficiencies or misrepresentations of the UTOPIA.

Three types of forcing data were used: (i) observations from an experimental campaign carried out during the 2008, 2009, and 2010 vegetative seasons in three Piedmontese vineyards, and (ii) values extracted from the freely available global database GLDAS (versions 2.0 and 2.1).

To answer to the scientific questions, different analyses have been considered:

- comparison of UTOPIA simulations driven by experimental datasets with observations;

- comparison of UTOPIA simulations driven by GLDAS datasets with observations;

- comparison of UTOPIA simulations driven by experimental datasets with those driven by GLDAS datasets;

- comparison of UTOPIA simulations driven by GLDAS datasets with the outputs of the NOAH model.

Note that, since the GLDAS2.0 database contains at least sixty years of gridded data, its use also allows for performing long-term simulations, in order to get a climatological database and eventually assess possible trends for surface or soil variables, to be eventually correlated with grapevine production and quality (this last point was already analyzed in [23]).

\section{Materials and Methods}

\subsection{The Observations}

Measurements were collected during the 2008, 2009, and 2010 vegetative seasons (e.g., from May to September) in three hilly sites (Cocconato, hereafter CO; Fubine, hereafter FB; and Castiglione Falletto, hereafter $\mathrm{CF}$ ), in which Barbera and Nebbiolo grapevines were planted.

In these sites, the vineyards were placed in rows $2.5 \mathrm{~m}$ apart from each other and trained on vertical shoot-positioned (VSP) systems, perpendicular to the contour lines (rittochino) at CC and aligned with them (giropoggio) at FB and CF. The orientation of the three slopes was south for CC, south-east for FB and east for $\mathrm{CF}$. Fast response velocity and temperature measurements were sampled at $21 \mathrm{~Hz}$ using a three-dimensional ultrasonic anemometer (Solent R2, Gill Instruments) installed at $3 \mathrm{~m}$ above the soil surface (i.e., about $1 \mathrm{~m}$ above the seasonal vegetation height peak).

Such measurements (air temperature, air humidity, photosynthetically active radiation, wind speed and direction, heat fluxes, net radiation, soil water content and temperature) were performed in the frame of the regional project MASGRAPE (adoption of a Multidisciplinary Approach to Study the GRAPEvine agro-ecosystem: analysis of biotic and abiotic factors able to influence yield and quality) and aimed to assess several factors related to grape productivity. The experimental campaign was described (the experiment outline and some preliminary results were published in [26]) and analyzed [27] in order to investigate vineyards microclimate and create a database of data suitable to perform the analysis of exchange processes between soil, vegetation and atmosphere, with a particular focus on the influence of terrain morphology and vineyards system. The fast response data, measured by sonic anemometers and Krypton lamps, were processed, to evaluate the turbulent fluxes of momentum, heat and water vapor, using the methods proposed in Reference [28], and subsequently the method of planar fit, proposed in Reference [29], was preferred to the one of double-triple rotation (described in Reference [28]) in order to neglect the effects of streamline distortion, eventually caused 
by the "rough" hilly surface. Finally, to prevent missing data in the dataset, interpolations were carried out on the data required by the LSM using the data of the neighbor stations [30-34] (see Appendix A).

\subsection{The Models: UTOPIA (University of Torino model of land Process Interaction with Atmosphere)}

The LSM selected for this study is the UTOPIA (University of Torino model of land Process Interaction with Atmosphere [22] (A minimal web page containing basic information about the UTOPIA is available here: http://personalpages.to.infn.it/ \{\}cassardo/utopia/utopia.html)). UTOPIA is a third-generation land surface model developed at the University of Torino (Physics Department) and is the upgraded version of the LSPM (Land Surface Process Model [35,36]). It is a diagnostic one-dimensional model studying the interactions at the interface between atmospheric surface layer, vegetation and soil.

Both models, UTOPIA and LSPM, were tested using measured data from experimental campaigns or coupled with an atmospheric circulation model.

The UTOPIA can be categorized as a big leaf model, meaning that a single vegetation element contributing to the various processes is considered, without considering its real extension. It is a soil multilayer model, where the number of the layers can be defined by the user. UTOPIA works on a single point in which the only direction allowed is the vertical one. Energy exchanges are evaluated by a resistance network taking into account the kind of surface. Momentum, heat and water vapor fluxes are the main processes considered. In addition, the model simulates the soil thermal, hydrological and photosynthetic processes.

UTOPIA needs, as mandatory requirements, some data to run: air temperature, specific or relative humidity, the two horizontal components of wind speed, precipitation rate (rain and/or snow), low and total cloudiness or solar global incoming radiation. Other variables, if not provided in input, are calculated in specific routines of the model. All UTOPIA simulations were initialized on 1 January 2007, e.g., about one year before the beginning of observations, in order to avoid any spin-up problem. In this analysis, the first year of UTOPIA simulations was not considered.

Vegetation parameters were initialized depending on vegetation code, which is a number identifying the main vegetation types in the world. The dataset used in the UTOPIA model is an extension [22] of the Land Cover/Vegetation type taken from Reference [20], and the code numbers employed for the UTOPIA simulation were: 10 (irrigated crop) and 26 (vineyards).

Soil parameters were taken from an extension [22] of the [37] soil texture table, where they are classified by soil type code. The types of soil are determined from the percentage of sand, silt and clay through the $[38,39]$ soil textural database.

\subsection{The Models: NOAH}

GLDAS contains the main outputs of the simulations carried out using the NOAH LSM. NOAH is an acronym deriving from the initial letters of the four agencies who collaborate for developing the model: National Centers for Environmental Prediction (NCEP), Oregon State University (OSU), the Air Force, and the Hydrology Research Laboratory at the National Weather Service. The NOAH is a well-known second generation LSM, incorporated in the WRF (Weather Research and Forecasting) mesoscale atmospheric model, and was evolved from the Oregon State University (OSU) model created in 1980s [40]. It can simulate water and energy fluxes, soil and land surface temperature, snow depth and snow water equivalent. The standard model configuration commonly has four soil layers and one vegetation canopy layer and includes a detailed snow parameterization. For further details about NOAH configuration, please refer to Reference [41]. We underline here that we did not run NOAH, but we just extracted the 3-hourly simulation outputs from GLDAS.

\subsection{Global Land Data Assimilation System (GLDAS)}

The GLDAS (Global Land Data Assimilation System) database was created and developed by NASA to assemble satellite and ground-based observational data products, using advanced land 
surface modelling and data assimilation techniques, in order to generate optimal fields of land surface states and fluxes [42]. It is available from the NASA Goddard Earth Sciences Data and Information Services Center (GES DISC).

The GLDAS archive, which is always in evolution, drives currently different land surface models: NOAH, Mosaic, Catchment, the Community Land Model (CLM) and the Variable Infiltration Capacity (VIC). Two different datasets compose the archive: GLDAS-1 and GLDAS-2. The first one consists of data with temporal coverage from 1979 to present (spatial resolution of $1.0^{\circ}$ ) and from 2000 to present (spatial resolution of $0.25^{\circ}$ ). Recently, GLDAS-2 was restructured into two components: GLDAS-2.0, forced entirely with the Princeton meteorological forcing data and currently extending from 1948 through 2010, and GLDAS-2.1, forced with a combination of models and observations based forcing datasets and extending from 2000 to present [43-45], with a monthly update. Regarding LSMs included in GLDAS, the GLDAS-2.0 simulations were initialized on 1 January 1948, using soil moisture and other state fields from the LSMs climatology for that day of the year, and were forced by the global meteorological forcing dataset from Princeton University [46]. The GLDAS-2.1 simulations were initialized using the conditions from the GLDAS-2.0 on 1 January 2000, and were forced with national oceanic and Atmospheric Administration (NOAA)/Global Data Assimilation System (GDAS) atmospheric analysis fields [47], the disaggregated Global precipitation Climatology Project (GPCP) precipitations fields [48], and the Air Force Weather Agency AGRicultural METeorological modelling system (AGRMET) radiation fields. Basic characteristics of the GLDAS-2 database are listed in Table 1.

Table 1. Basic description of Global Land Data Assimilation System (GLDAS)-2 products.

\begin{tabular}{cc}
\hline Characteristic & Value \\
\hline Latitude extent & $-60^{\circ}$ to $90^{\circ}$ \\
\hline Longitude extent & $-180^{\circ}$ to $180^{\circ}$ \\
\hline Spatial resolution & $1.0^{\circ}, 0.25^{\circ}$ \\
\hline Temporal resolution & 3-hourly, monthly \\
\hline Temporal coverage & GLDAS-2.0: 03Z 1 January $1948-21 \mathrm{Z} 31$ December 2010 \\
Gimension & GLD (lon) $\times 150$ (lat) for the $1.0^{\circ} \times 1.0^{\circ}$ data products \\
& 1440 (lon) $\times 600$ (lat) for the $0.25^{\circ} \times 0.25^{\circ}$ data products \\
\hline Origin (1st grid center) & $(179.5 \mathrm{~W}, 59.5 \mathrm{~S})$ for the $1.0^{\circ} \times 1.0^{\circ}$ data products \\
Land surface models & $(179.875 \mathrm{~W}, 59.875 S)$ for the $0.25^{\circ} \times 0.25^{\circ}$ data products \\
\hline
\end{tabular}

GLDAS represents an important data source for global water cycle research, and its products were evaluated by many studies. A systematic evaluation of the monthly scale precipitation and temperature forcing inputs of GLDAS-2.0-2.1 over China was performed in Reference [49]: in this study, the authors demonstrated that air temperature and humidity from the GLDAS-1/NOAH model had a high accuracy, while downward solar radiation and wind speed data results were overestimated [50]. Another study related to the four LSMs included in GLDAS-1 showed different estimates of river discharge and distinct geographic patterns in the accuracy of each model, when compared with gauged discharge data [51]. In addition, the simulation of moisture of first soil layer $(0-5 \mathrm{~cm})$ resulted underestimated. Other authors [52], instead, discovered that the four models included in GLDAS simulated well the soil moisture of the $20-40 \mathrm{~cm}$ layer over the Tibetan Plateau.

\subsection{Methods}

In this paper, we describe the five different simulations carried out with UTOPIA driven by observations in the vineyards and by data extracted by GLDAS-2.0 and GLDAS-2.1 (since the selected period was included in both datasets), in which the vegetation type was set respectively to vineyards 
and irrigated crops. The data were extracted from GLDAS in the three grid points nearest to the three selected vineyards, whose coordinates are reported in Table 2. The second vegetation type (irrigated crops) was selected in order to compare UTOPIA outputs with NOAH simulations already included in GLDAS: in fact, the land use selected in NOAH simulations in the three grid points is irrigated crops. Regarding soil types, we performed the UTOPIA simulations driven by GLDAS data prescribing the soil types used by NOAH in the three grid points, while the soil types deduced by in-situ measurements performed in the three sites were used for the UTOPIA simulations driven by the observations. The list of simulations and their names used in the paper, as well as vegetation and soil types used, are reported in Table 3.

Table 2. Coordinates of the three experimental sites.

\begin{tabular}{ccccc}
\hline Vineyard & Abbreviation & Latitude & Longitude & Elevation (m a.s.l.) \\
\hline Cocconato & $\mathrm{CO}$ & $45^{\circ} 05^{\prime} \mathrm{N}$ & $8^{\circ} 03^{\prime} \mathrm{E}$ & 311 \\
Fubine & $\mathrm{FB}$ & $44^{\circ} 58^{\prime} \mathrm{N}$ & $8^{\circ} 26^{\prime} \mathrm{E}$ & 210 \\
Castiglione Falletto & $\mathrm{CF}$ & $44^{\circ} 37^{\prime} \mathrm{N}$ & $7^{\circ} 59^{\prime} \mathrm{E}$ & 275 \\
\hline
\end{tabular}

Table 3. Summary of experiments performed, with the explicit indication of the boundary condition used, as well as vegetation and soil types. For NOAH, we have retrieved the data from the GLDAS web site. Italic style indicates that the types of vegetation and soil were set by the GLDAS team. For soil types, the three numbers refer, respectively, to the sites: CF, CO, and FB. The used soil types are thus defined in the following way: 4 (silt loam), 5 (loam), 7 (silty clay loam), 8 (clay loam).

\begin{tabular}{cccccc}
\hline$\#$ & Experiment & LSM & Boundary Conditions & Vegetation Type & Soil Type \\
\hline 1 & EXP1a & UTOPIA & $\begin{array}{c}\text { Vineyards } \\
\text { observations } \\
\text { Vineyards } \\
\text { observations }\end{array}$ & Vineyards & $4,7,5$ \\
2 & EXP1b & UTOPIA & GLDAS-2.1 & Vineyards & $4,7,5$ \\
3 & EXP2a & UTOPIA & GLDAS-2.1 & Irrigated crop & $5,5,8$ \\
4 & EXP2b & UTOPIA & GLDAS-2.0 & Vineyards & $5,5,8$ \\
5 & EXP3a & UTOPIA & GLDAS-2.0 & Irrigated crop & $5,5,8$ \\
6 & EXP3b & UTOPIA & From GLDAS-2.1 & Irrigated crop & $5,5,8$ \\
7 & EXP4 & NOAH & From GLDAS-2.0 & Irrigated crop & $5,5,8$ \\
8 & EXP5 & NOAH & & &
\end{tabular}

The results were compared with energy budget components (net radiation, turbulent fluxes of sensible and latent heat), soil temperature and water content measurements, carried out during the experimental campaign.

Two types of comparisons were performed. In a preliminary step, the aim was to compare if UTOPIA can give a satisfactory representation of such variables. In this case, the selected simulations were the EXP1a, EXP2a, and EXP3a, in which the vegetation type chosen for UTOPIA was vineyards. The aim of the experiments was twofold: from one hand, to verify the UTOPIA behavior over a complex terrain as a specific vineyard, and from the other hand to see how and how much the use of GLDAS input instead of observations was degrading the quality of outputs.

The other simulations (EXP1b, EXP2b, and EXP3b), in which the vegetation type selected was irrigated crops, were considered in order to see which kind of difference in output data was present using the land use extracted by GLDAS.

The second intercomparison was instead aimed to compare UTOPIA and NOAH between each other. In this case, the comparison was performed using "irrigated crop" as vegetation type, in order to have UTOPIA and NOAH initialized uniformly (thus EXP2b and EXP3b were compared with EXP4 and EXP5), to have an indication of the uncertainty in using different land use.

\section{Results}

As already pointed out, the evaluated time period involved three years (2008-2010) and three stations ( $\mathrm{CF}, \mathrm{CO}$, and FB: see Table 2). The variables used for the intercomparisons are: net radiation 
(RNET, available at CF and CO), sensible heat flux (SHF, measured at all stations), latent heat flux (LHF, available at FB), soil temperature (TS, available at $\mathrm{CO}$ and $\mathrm{FB}$ ), and soil volumetric water content (VWC, available at CO), both relative to the first soil layers, $10 \mathrm{~cm}$ deep. Statistical results of intercomparisons were shown in comprehensive tables containing all values, while figures depict only the most relevant results, by using violin plots, and are reported in the Supplementary material. In all cases, the original data are expressed as daily means. A preliminary analysis on three input data used in the UTOPIA simulations (solar global radiation, precipitation, and temperature) is reported in the first subsection, with the aim of underlining the differences in the forcing data and possibly interpret eventual differences in the output data.

\subsection{Input Data Intercomparison}

The input data used as forcing for UTOPIA simulations in experiments EXP1-3 come from the observations carried out in the three experimental vineyards mentioned above, and from the two databases, GLDAS2.0 and GLDAS2.1. While the observations refer to a specific environment and have been measured within the vineyards, with the sensors located above the vegetation, the data of GLDAS belong to a database of gridded data in which each grid point, at the latitudes of the three vineyards, refer to an area of about $225 \mathrm{~km}^{2}$, in which the conformation of the territory is smoothed and thus the site characteristics are different. In addition, the two GLDAS databases have been created using different "data" sources, with a massive use of model outputs to accomplish for the irregular distribution of available observations. Differences in the data are thus expected. An inspection on Tables S1-S18, in the Supplementary Data section, confirm the expectations and allows for quantifying these differences. Moreover, differences are similar in the three sites.

Regarding solar global radiation, for instance, we can see that GLDAS2.1 data are closer than GLDAS2.0 data to the observations, particularly concerning the range of the data distribution and the correlation. Differences of mean values between GLDAS2.1 and observations are about $5-15 \mathrm{~W} \mathrm{~m}^{-2}$, and standard deviations are similar, while for GLDAS2.0 differences are $0-40 \mathrm{~W} \mathrm{~m}^{-2}$, and standard deviations are much lower. Minima and maxima are often not well captured, thus, range is much lower for GLDAS2.0.

Regarding precipitation, the two GLDAS databases show similar distributions and tend to exceed the observations, in terms of mean values, maxima, standard deviations, and ranges, however, they are well correlated with observations.

Finally, air temperature shows some differences generally larger for GLDAS2.0 than GLDAS2.1 for each statistical parameter: mean values of GLDAS2.1 are lower than observations $\left(0.5-2.5^{\circ} \mathrm{C}\right)$ while those of GLDAS2.0 are higher $\left(0.2-1.2^{\circ} \mathrm{C}\right)$, ranges and standard deviations are slightly (quite) smaller than those of observations for GLDAS2.1 (GLDAS2.0), with minima higher for GLDAS2.0, and correlation coefficients are closer to 1 for GLDAS2.1.

\subsection{UTOPIA (University of TOrino land surface Process Interaction model in Atmosphere) Simulations Compared with Observations}

The experiments considered in this subsection are EXP1a, EXP2a, and EXP3a, compared with the observations (OBS) in the vineyards, if any. In order to consider the effect of having a different vegetation type, also experiments EXP1b, EXP2b, and EXP3b were considered. The comparison was carried out only in the days in which observations were sufficient, in number, to evaluate a daily mean, the number of data, thus, changes for each variable and is indicated in the Tables.

\subsubsection{Net Radiation (RNET)}

In the CO station (Table 4, Figures S1 and S24), EXP1 and EXP2 have quite similar results, with maxima slightly lower for EXP2, while EXP3 cuts both minima and maxima, resulting in a lower range. Experiments " $b$ " have maxima slightly larger than those of experiments "a". This is not surprising, considering that net radiation is inversely proportional to albedo, since albedo of vineyards 
(0.23, experiment " $\mathrm{a}$ ") exceeds the one of irrigated crops $(0.18$, " $\mathrm{b}$ "). EXP1b/2b have distributions closer to the observations, and the uncertainty of the mean value for EXP1a is about $20 \mathrm{~W} \mathrm{~m}^{-2}$ and rises to about $25 \mathrm{~W} \mathrm{~m}^{-2}$ for EXP3a. Both values are reasonable, especially considering that the typical measurement error of a radiometer (that measures the most important component of net radiation, e.g., the incident solar radiation) in standard commercial sensors is $20-30 \mathrm{~W} \mathrm{~m}^{-2}$.

Table 4. Net Radiation (RNET) $\left(\mathrm{W} \mathrm{m}^{-2}\right.$ ) simulated and observed at CO station (data number 515).

\begin{tabular}{cccccccc}
\hline & Bias & Mean & $\boldsymbol{\sigma}$ & Median & Min & Max & Range \\
\hline EXP1a & -19.3 & 66.6 & 64.4 & 63.8 & -48.3 & 199.5 & 247.8 \\
EXP2a & -20.5 & 65.4 & 70.9 & 60.2 & -50.3 & 192.3 & 242.6 \\
EXP3a & -26.6 & 59.3 & 54.5 & 60.3 & -31.9 & 152.0 & 183.9 \\
OBS & $\mathbf{0 . 0}$ & $\mathbf{8 5 . 9}$ & $\mathbf{7 7 . 4}$ & $\mathbf{7 0 . 3}$ & $\mathbf{- 4 5 . 9}$ & $\mathbf{2 3 5 . 4}$ & $\mathbf{2 8 1 . 3}$ \\
EXP1b & -11.6 & 74.3 & 69.6 & 72.9 & -48.6 & 220.1 & 268.7 \\
EXP2b & -12.4 & 73.5 & 76.1 & 67.6 & -50.2 & 209.7 & 259.9 \\
EXP3b & -18.0 & 67.9 & 58.0 & 69.9 & -33.3 & 169.5 & 202.8 \\
\hline
\end{tabular}

\subsubsection{Sensible Heat Flux (SHF)}

Even if the number of days in which it is possible to evaluate a daily mean is limited (sonic anemometer was only installed during the vegetative season), analyzing the statistical values reported into Tables 5-7, and looking at Supplementary Figures S2-S4, S25 and S26, it is evident that the simulations tend to amplify the range with respect to observed values, showing some negative values, especially when GLDAS-2.0,2.1 is used and the vegetation is irrigated crop. In more detail, EXP1a shows mean and median values closer to observations (about $2-20 \mathrm{~W} \mathrm{~m}^{-2}$ of difference) than EXP2a ( 9-23 $\mathrm{W} \mathrm{m}^{-2}$ of difference) and EXP3a (difference: $\sim 22-28 \mathrm{~W} \mathrm{~m}^{-2}$ ) in all stations, due to the maxima being too low in EXP2a and in EXP3a, while EXP1b shows larger mean values $\left(\sim 28-50 \mathrm{~W} \mathrm{~m}^{-2}\right.$ of difference). EXP2b values (difference: $\sim 2-10 \mathrm{~W} \mathrm{~m}^{-2}$ ) seem more similar to the observations than EXP3b ones (difference: $\sim 10-16 \mathrm{~W} \mathrm{~m}^{-2}$ ), but all " $\mathrm{b}$ " experiments show extremes too large (in absolute value), with quite negative values in EXP2b and EXP3b, thus producing ranges even four times bigger than the observations (as for EXP2b in FB). Thus, in the case of sensible heat flux (SHF), the use of vineyards as vegetation type appears fundamental in getting the best results, and the use of GLDAS-2.0,2.1 data as boundary conditions slightly deteriorates the quality of the outputs, even if the differences, on daily basis, remain approximately in the range $20-30 \mathrm{~W} \mathrm{~m}^{-2}$, value that could also be considered as the typical uncertainty of measurements with sonic anemometers [53,54].

Table 5. Sensible Heat Flux (SHF) $\left(\mathrm{W} \mathrm{m}^{-2}\right.$ ) simulated and observed at the CF station (data number 271).

\begin{tabular}{cccccccc}
\hline & Bias & Mean & Standard Deviation & Median & Min & Max & Range \\
\hline EXP1a & -2.8 & 34.4 & 25.6 & 24.7 & 3.6 & 118.6 & 115.0 \\
EXP2a & -23.3 & 13.9 & 21.9 & 10.7 & -33.0 & 88.2 & 121.2 \\
EXP3a & -27.1 & 10.1 & 15.3 & 9.6 & -26.8 & 50.8 & 77.6 \\
OBS & $\mathbf{0 . 0}$ & $\mathbf{3 7 . 2}$ & $\mathbf{1 8 . 0}$ & $\mathbf{3 6 . 3}$ & $\mathbf{- 5 2 . 0}$ & $\mathbf{8 6 . 2}$ & $\mathbf{9 1 . 4}$ \\
EXP1b & 27.8 & 65.0 & 46.4 & 55.3 & 4.4 & 156.5 & 152.1 \\
EXP2b & 1.1 & 38.3 & 51.5 & 15.6 & -79.0 & 151.1 & 230.1 \\
EXP3b & -9.1 & 28.1 & 35.2 & 16.8 & -44.5 & 107.3 & 151.8 \\
\hline
\end{tabular}

Table 6. SHF $\left(\mathrm{W} \mathrm{m}^{-2}\right)$ simulated and observed at the CO station (data number 354).

\begin{tabular}{cccccccc}
\hline & Bias & Mean & Standard Deviation & Median & Min & Max & Range \\
\hline EXP1a & 1.4 & 35.6 & 26.2 & 25.5 & 1.9 & 130.6 & 128.1 \\
EXP2a & -8.9 & 25.3 & 26.5 & 19.2 & -54.7 & 96.9 & 151.6 \\
EXP3a & -26.3 & 7.9 & 14.9 & 6.8 & -33.8 & 46.9 & 80.7 \\
OBS & $\mathbf{0 . 0}$ & $\mathbf{3 4 . 2}$ & $\mathbf{1 6 . 1}$ & $\mathbf{3 3 . 8}$ & -5.5 & $\mathbf{7 7 . 1}$ & $\mathbf{8 2 . 6}$ \\
EXP1b & 29.1 & 63.3 & 46.9 & 43.2 & 2.8 & 162.7 & 159.9 \\
EXP2b & 10.7 & 44.9 & 50.5 & 23.5 & -80.7 & 143.8 & 224.5 \\
EXP3b & -15.5 & 18.7 & 26.8 & 11.9 & -47.5 & 105.3 & 152.8 \\
\hline
\end{tabular}


Table 7. SHF $\left(\mathrm{W} \mathrm{m}^{-2}\right)$ simulated and observed at the FB station (data number 323).

\begin{tabular}{cccccccc}
\hline & Bias & Mean & Standard Deviation & Median & Min & Max & Range \\
\hline EXP1a & 19.5 & 48.3 & 33.1 & 34.8 & 3.5 & 143.9 & 140.4 \\
EXP2a & -9.6 & 19.2 & 22.1 & 14.3 & -43.4 & 88.2 & 131.6 \\
EXP3a & -2.9 & 6.9 & 16.3 & 5.0 & -34.0 & 49.3 & 83.3 \\
OBS & $\mathbf{0 . 0}$ & $\mathbf{2 8 . 8}$ & $\mathbf{1 3 . 3}$ & $\mathbf{3 0 . 0}$ & -7.5 & $\mathbf{6 4 . 4}$ & $\mathbf{7 1 . 9}$ \\
EXP1b & 49.9 & 78.7 & 55.0 & 72.4 & 4.4 & 182.0 & 177.6 \\
EXP2b & 4.9 & 33.7 & 45.0 & 13.2 & -99.5 & 150.9 & 250.4 \\
EXP3b & -7.2 & 21.6 & 33.0 & 11.3 & -44.1 & 107.5 & 151.6 \\
\hline
\end{tabular}

\subsubsection{Latent Heat Flux (LHF)}

Regarding latent heat flux (LHF), measurement was available only at FB (Table 8, Figures S5 and S27). Despite only about the $40 \%$ of data in the three vegetative seasons was measured, the number of available data allows a comparison. The observation range appears slightly larger than the one of SHF, without negative values as for SHF. EXP1a values have the peak of the distribution in the lower range $\left(0-50 \mathrm{~W} \mathrm{~m}^{-2}\right)$ and too large maxima (over $100 \mathrm{~W} \mathrm{~m}^{-2}$ ). EXP2a values are equally distributed in the range $0-150 \mathrm{~W} \mathrm{~m}^{-2}$, with peaks at about $200 \mathrm{~W} \mathrm{~m}^{-2}$. EXP3a values have a lower range with the peak of the distribution in the range $50-100 \mathrm{~W} \mathrm{~m}^{-2}$. The output relative to experiments " $\mathrm{b}$ " show characteristics similar to those of the "a" ones, but with larger maxima. As a summary, the maxima are overestimated by UTOPIA in all simulations.

Table 8. Latent heat flux (LHF) $\left(\mathrm{W} \mathrm{m}^{-2}\right)$ simulated and observed at the FB station (data number 268).

\begin{tabular}{cccccccc}
\hline & Bias & Mean & Standard Deviation & Median & Min & Max & Range \\
\hline EXP1a & 6.8 & 74.4 & 57.2 & 44.5 & 8.9 & 189.3 & 180.4 \\
EXP2a & 28.2 & 95.8 & 50.7 & 96.1 & 6.1 & 204.6 & 198.5 \\
EXP3a & 20.7 & 88.3 & 28.6 & 89.3 & 17.2 & 154.3 & 137.1 \\
OBS & $\mathbf{0 . 0}$ & $\mathbf{6 7 . 6}$ & $\mathbf{2 4 . 4}$ & $\mathbf{7 0 . 1}$ & $\mathbf{1 1 . 1}$ & $\mathbf{1 2 4 . 9}$ & $\mathbf{1 1 3 . 8}$ \\
EXP1b & -13.5 & 54.1 & 52.5 & 29.6 & 8.7 & 226.0 & 217.3 \\
EXP2b & 22.6 & 90.2 & 59.0 & 77.3 & 7.6 & 296.0 & 288.4 \\
EXP3b & 13.1 & 80.7 & 38.0 & 82.3 & 19.1 & 186.6 & 167.5 \\
\hline
\end{tabular}

\subsubsection{Soil Temperature (TS)}

Soil temperature (TS) in the upper soil layer $(0-10 \mathrm{~cm}$, Tables 9 and 10 and Supplementary Figures S6 and S7) were observed in CO and FB. Surprisingly, the worse result is the one of EXP1, which shows the largest difference in mean and median values, and the largest standard deviation due to the more extreme minima (underestimation by about $4{ }^{\circ} \mathrm{C}$ ) and maxima (overestimation by about $5-7$ ${ }^{\circ} \mathrm{C}$ ), and consequent larger range. Simulations with GLDAS2.1 give similar outputs than EXP1, with lower maxima and similar minima, and a larger number of values in the lower half of the distribution. The initialization with GLDAS-2.0 seems to give the best results in both stations, with minima slightly lower than the observations. It is also noticeable that, for the TS variable, the differences between the two vegetation types are small.

Table 9. Soil temperature (TS) $\left({ }^{\circ} \mathrm{C}\right)(0-10 \mathrm{~cm})$ simulated and observed at the $\mathrm{CO}$ station (data number 494).

\begin{tabular}{cccccccc}
\hline & Bias & Mean & Standard Deviation & Median & Min & Max & Range \\
\hline EXP1a & 1.1 & 16.2 & 10.8 & 17.7 & -2.9 & 32.9 & 35.8 \\
EXP2a & -2.3 & 12.8 & 8.5 & 13.1 & -2.9 & 29.2 & 32.1 \\
EXP3a & 0.5 & 15.6 & 7.5 & 16.3 & -2.0 & 27.7 & 29.7 \\
OBS & $\mathbf{0 . 0}$ & $\mathbf{1 5 . 1}$ & $\mathbf{7 . 5}$ & $\mathbf{1 5 . 9}$ & $\mathbf{1 . 3}$ & $\mathbf{2 7 . 8}$ & $\mathbf{2 6 . 5}$ \\
EXP1b & 0.9 & 16.0 & 9.9 & 17.2 & -2.8 & 31.4 & 34.2 \\
EXP2b & -2.1 & 13.0 & 8.2 & 13.5 & -2.9 & 28.6 & 31.5 \\
EXP3b & 0.5 & 15.6 & 7.2 & 16.3 & -2.0 & 27.5 & 29.5 \\
\hline
\end{tabular}


Table 10. TS $\left({ }^{\circ} \mathrm{C}\right)(0-10 \mathrm{~cm})$ simulated and observed at the FB station (data number 400$)$.

\begin{tabular}{cccccccc}
\hline & Bias & Mean & Standard Deviation & Median & Min & Max & Range \\
\hline EXP1a & 2.0 & 18.2 & 11.9 & 21.3 & -3.0 & 34.9 & 37.9 \\
EXP2a & -1.1 & 15.1 & 9.9 & 17.3 & -2.6 & 30.2 & 32.8 \\
EXP3a & -0.1 & 16.1 & 8.4 & 18.4 & -0.6 & 27.8 & 28.4 \\
OBS & $\mathbf{0 . 0}$ & $\mathbf{1 6 . 2}$ & $\mathbf{8 . 8}$ & $\mathbf{1 9 . 1}$ & $\mathbf{1 . 2}$ & $\mathbf{2 8 . 3}$ & $\mathbf{2 7 . 1}$ \\
EXP1b & 1.3 & 17.5 & 11.3 & 20.0 & -3.1 & 32.8 & 35.9 \\
EXP2b & -1.2 & 15.0 & 9.7 & 17.6 & -2.6 & 29.8 & 32.4 \\
EXP3b & -0.1 & 16.1 & 8.2 & 18.5 & -0.6 & 27.7 & 28.3 \\
\hline
\end{tabular}

In the case of TS, the obtained differences exceed the instrumental precision (which can be assumed as $0.1^{\circ} \mathrm{C}$ ). However, as it can be seen in Supplementary Figure S28, the simulations appear shifted with respect to observations, while fluctuations of daily values are captured, as testified by the high values of the correlation coefficient (Supplementary Table S19).

\subsubsection{Soil Moisture (VWC)}

The soil volumetric water content $(\mathrm{VWC})$ of the upper layer $(0-10 \mathrm{~cm})$, expressed in $\mathrm{m}^{3}{ }_{\text {water }}$ $\mathrm{m}^{-3}$ soil, reveals a surprising behavior (Table 11 and Figure S8). The observation range is quite extended, from 0.10 to $0.40 \mathrm{~m}^{3}$ water $\mathrm{m}^{-3}$ soil, but with very few observations larger than $0.30 \mathrm{~m}^{3}$ water $\mathrm{m}^{-3}$ soil. The soil of the site in $\mathrm{CO}$ belongs to the category of the silty clay loam. None of the simulations is able to reach values lower than the respective wilting point (which is $0.22 \mathrm{~m}^{3}$ water $\mathrm{m}^{-3}$ soil for EXP1 and $0.15 \mathrm{~m}^{3}$ water $\mathrm{m}^{-3}$ soil for EXP2/3, in which soil belongs to the category of loam), except for the simulation 1a. Almost all simulations calculate a volumetric soil moisture whose distributions differ from the observed one: the majority of values are comprised in the range $0.25-0.40 \mathrm{~m}^{3}$ water $\mathrm{m}^{-3}$ soil for EXP1 and 0.30-0.40 $\mathrm{m}^{3}$ water $\mathrm{m}^{-3}$ soil for EXP2/3. Furthermore, EXP1a contains values lower that the wilting point for that soil $\left(0.22 \mathrm{~m}^{3}\right.$ water $\mathrm{m}^{-3}$ soil $)$. As a result, simulated maxima values almost coincide with observed ones, while minima are overestimated, thus producing mean and median values overestimated. Mean and median values of EXP1a, $b$ and EXP3a, $b$ were coincident. Considering mean values, EXP1a, b were closer to the observed ones.

Table 11. Volumetric water content (VWC) $\left(\mathrm{m}^{3} \mathrm{~m}^{-3}\right)(0-10 \mathrm{~cm})$ simulated and observed at the CO station (data number 427).

\begin{tabular}{cccccccc}
\hline & Bias & Mean & Standard Deviation & Median & Min & Max & Range \\
\hline EXP1a & 0.09 & 0.29 & 0.06 & 0.31 & 0.16 & 0.44 & 0.28 \\
EXP2a & 0.11 & 0.31 & 0.06 & 0.33 & 0.18 & 0.41 & 0.23 \\
EXP3a & 0.13 & 0.33 & 0.04 & 0.35 & 0.23 & 0.42 & 0.19 \\
OBS & $\mathbf{0 . 0}$ & $\mathbf{0 . 2}$ & $\mathbf{0 . 0 6}$ & $\mathbf{0 . 2 2}$ & $\mathbf{0 . 0 9}$ & $\mathbf{0 . 4 2}$ & $\mathbf{0 . 3 3}$ \\
EXP1b & 0.09 & 0.29 & 0.06 & 0.31 & 0.21 & 0.42 & 0.21 \\
EXP2b & 0.12 & 0.32 & 0.05 & 0.33 & 0.23 & 0.41 & 0.18 \\
EXP3b & 0.13 & 0.33 & 0.04 & 0.35 & 0.25 & 0.41 & 0.16 \\
\hline
\end{tabular}

\subsection{Intercomparison between UTOPIA and NOAH Simulations Initialized with GLDAS}

The experiments considered in this intercomparison are EXP2b, EXP3b for UTOPIA and EXP4, EXP5 for NOAH. In EXP2b and EXP4 the boundary conditions used are retrieved from GLDAS2.1 and in EXP3b and EXP5 from GLDAS2.0. Since vegetation type for NOAH was "irrigated crops", only UTOPIA simulations with the same vegetation type were considered, to avoid any problem of result interpretation. In any case, previous subsection already investigated the role of vegetation type in UTOPIA simulations. Finally, as in this section the intercomparison involve only model simulations and not observations, the dataset includes all days in the considered three-year period, and, as a result, the values are different from those in Tables 4-11. 


\subsubsection{Net Radiation (RNET)}

The values of RNET estimated by NOAH (Tables 12-14 and Supplementary Figures S9-S11) show daily mean and median values larger than those evaluated by UTOPIA (by about $40-50 \mathrm{~W} \mathrm{~m}^{-2}$ ). In addition, maxima and minima are higher for NOAH (by about $30-50 \mathrm{~W} \mathrm{~m}^{-2}$ the former and 20-30 $\mathrm{W} \mathrm{m}^{-2}$ the latter). In previous section EXP1,2,3a show that, compared with the observations, UTOPIA maxima are too low, while minima are consistent, with discrepancies of a similar magnitude, and comparable with the accuracy of solar radiation measurements. Here, UTOPIA and NOAH values differ by about $20-30 \mathrm{~W} \mathrm{~m}^{-2}$, the former being lower than the latter, for both GLDAS2.0 and GLDAS2.1. Regarding value distribution, the most frequent for NOAH are in the class $150-200 \mathrm{~W} \mathrm{~m}^{-2}$, while for UTOPIA they are around $0 \mathrm{~W} \mathrm{~m}^{-2}$. As a conclusion, it seems that both models (UTOPIA and NOAH) can give a sufficiently good representation of the net radiation (NOAH overestimating the minima, and UTOPIA underestimating the maxima). We also notice that the initializations with GLDAS-2.0 (EXP3b and EXP5) show the smallest ranges for both models, because minima are higher and maxima smaller, and in EXP5 minima are never negative in all sites, while observed minima in vineyards at CO (Table 13) are negative and correctly captured by UTOPIA (EXP1,2,3a). Thus, it seems that GLDAS-2.1 gives more correct boundary conditions for RNET to LSMs.

Table 12. RNET $\left(\mathrm{W} \mathrm{m}^{-2}\right)$ simulated by UTOPIA and NOAH, initialized with GLDAS, at the CF station.

\begin{tabular}{ccccccc}
\hline & Mean & Standard Deviation & Median & Min & Max & Range \\
\hline EXP2b & 80.9 & 75.0 & 71.8 & -46.2 & 222.7 & 268.9 \\
EXP4 & 129.9 & 82.3 & 135.0 & -21.2 & 266.1 & 287.3 \\
EXP3b & 69.3 & 55.4 & 71.1 & -33.5 & 170.5 & 204.0 \\
EXP5 & 117.4 & 56.8 & 130.5 & 8.5 & 213.1 & 204.6 \\
\hline
\end{tabular}

Table 13. RNET $\left(\mathrm{W} \mathrm{m}^{-2}\right)$ simulated by UTOPIA and NOAH, initialized with GLDAS, at the CO station.

\begin{tabular}{ccccccc}
\hline & Mean & Standard Deviation & Median & Min & Max & Range \\
\hline EXP2b & 71.2 & 76.1 & 61.0 & -50.2 & 215.4 & 265.6 \\
EXP4 & 113.5 & 88.5 & 121.4 & -25.0 & 252.6 & 277.6 \\
EXP3b & 66.8 & 57.6 & 68.1 & -37.6 & 169.5 & 207.1 \\
EXP5 & 118.8 & 55.5 & 132.8 & 9.3 & 211.3 & 202.0 \\
\hline
\end{tabular}

Table 14. RNET $\left(\mathrm{W} \mathrm{m}^{-2}\right)$ simulated by UTOPIA and NOAH, initialized with GLDAS, at the FB station.

\begin{tabular}{ccccccc}
\hline & Mean & Standard Deviation & Median & Min & Max & Range \\
\hline EXP2b & 72.4 & 73.8 & 61.4 & -46.6 & 215.2 & 261.8 \\
EXP4 & 125.7 & 84.5 & 127.4 & -23.8 & 268.6 & 292.4 \\
EXP3b & 65.7 & 55.6 & 67.4 & -36.0 & 165.9 & 201.9 \\
EXP5 & 116.1 & 55.9 & 129.1 & 8.1 & 210.5 & 202.4 \\
\hline
\end{tabular}

\subsubsection{Sensible Heat Flux (SHF)}

SHF mean and median values (Tables 15-17 and Supplementary Figures S12-S14) differ by $0-25 \mathrm{~W} \mathrm{~m}^{-2}$ between NOAH and UTOPIA, NOAH values being larger (except for the CO station): these differences are compatible with SHF measurement errors using fast response instruments $[53,54]$. However, individual values (daily means) differ more, as it may be seen looking at ranges and extremes. UTOPIA ranges are larger than those of NOAH. One reason is that, compared to NOAH, minima of UTOPIA are lower $\left(10-80 \mathrm{~W} \mathrm{~m}^{-2}\right)$, while maxima are higher $\left(20-90 \mathrm{~W} \mathrm{~m}^{-2}\right)$. Also considering the results of EXP1,2,3a (Tables 5-7), perhaps both models capture the mean value of daily means and can be considered able to get the climatology of the sites, but individual NOAH daily values may be considered more accurate. 
Table 15. SHF $\left(\mathrm{W} \mathrm{m}^{-2}\right)$ simulated by UTOPIA and NOAH, initialized with GLDAS, at the CF station.

\begin{tabular}{ccccccc}
\hline & Mean & Standard Deviation & Median & Min & Max & Range \\
\hline EXP2b & 16.6 & 41.2 & 2.0 & -79.0 & 151.1 & 230.1 \\
EXP4 & 28.2 & 29.0 & 27.1 & -45.4 & 139.4 & 184.8 \\
EXP3b & 14.2 & 29.0 & 5.6 & -55.1 & 112.7 & 167.8 \\
EXP5 & 28.2 & 25.6 & 30.9 & -57.5 & 83.8 & 141.3 \\
\hline
\end{tabular}

Table 16. SHF $\left(\mathrm{W} \mathrm{m}^{-2}\right)$ simulated by UTOPIA and NOAH, initialized with GLDAS, at the CO station.

\begin{tabular}{ccccccc}
\hline & Mean & Standard Deviation & Median & Min & Max & Range \\
\hline EXP2b & 19.8 & 43.7 & 4.6 & -80.7 & 143.8 & 224.5 \\
EXP4 & 4.5 & 16.3 & 3.3 & -86.4 & 56.6 & 143.0 \\
EXP3b & 7.9 & 21.4 & 3.0 & -58.1 & 105.3 & 163.4 \\
EXP5 & 24.9 & 23.6 & 28.1 & -46.0 & 71.0 & 117.0 \\
\hline
\end{tabular}

Table 17. SHF $\left(\mathrm{W} \mathrm{m}^{-2}\right)$ simulated by UTOPIA and NOAH, initialized with GLDAS, at the FB station.

\begin{tabular}{ccccccc}
\hline & Mean & Standard Deviation & Median & Min & Max & Range \\
\hline EXP2b & 16.0 & 37.5 & 4.9 & -99.5 & 150.9 & 250.4 \\
EXP4 & 17.4 & 20.4 & 14.3 & -36.4 & 94.5 & 130.9 \\
EXP3b & 11.1 & 27.0 & 3.3 & -59.6 & 110.3 & 169.9 \\
EXP5 & 12.2 & 17.8 & 13.2 & -42.7 & 51.1 & 93.8 \\
\hline
\end{tabular}

Regarding the two versions of GLDAS, results are puzzling: often, but not always, GLDAS-2.1-based mean values exceed those based on GLDAS-2.0, while ranges of GLDAS-2.1 simulations are larger than those of GLDAS-2.0 ones. Ranges of GLDAS2.1 are larger than those of GLDAS2.0 in almost every site, and maxima of EXP5 (NOAH) appear truncated above $50-70 \mathrm{~W} \mathrm{~m}^{-2}$ (Supplementary Figures S12-S14). For this reason, it is not clear to conclude which version would provide more reasonable values.

\subsubsection{Latent Heat Flux (LHF)}

LHF, in terms of differences among mean and median values, shows similar results between the two models and the two versions of GLDAS, with mean differences of about $0-15 \mathrm{~W} \mathrm{~m}^{-2}$ (Tables 18-20 and Supplementary Figures S15-S17) with respect to SHF. The larger range of UTOPIA simulations (about $60-130 \mathrm{~W} \mathrm{~m}^{-2}$ ) and the more extreme values of extremes (for UTOPIA, minima are about $-2-20 \mathrm{~W} \mathrm{~m}^{-2}$ lower, and maxima about $40-120 \mathrm{~W} \mathrm{~m}^{-2}$ higher) indicate a situation similar to that for SHF, but with larger values and weaker deviations. In particular, the LHF maxima reached by UTOPIA sometimes exceed net radiation (in EXP2b and sometimes EXP3b), causing SHF to be negative in those occasions. This is not occurring for NOAH. Also, regarding the two versions of GLDAS, conclusions are similar to those for the SHF variable (often, but not always, GLDAS-2.1-based mean values exceed those based on GLDAS-2.0, while ranges of GLDAS-2.1 simulations are larger than those of GLDAS-2.0 ones). Thus, also for LHF, we can conclude that perhaps both models capture the mean value of daily means and can be considered able to get the climatology of the sites, but individual NOAH daily values may be considered more accurate.

Table 18. LHF $\left(\mathrm{W} \mathrm{m}^{-2}\right)$ simulated by UTOPIA and NOAH, initialized with GLDAS, at the CF station.

\begin{tabular}{ccccccc}
\hline & Mean & Standard Deviation & Median & Min & Max & Range \\
\hline EXP2b & 61.8 & 61.0 & 40.0 & -17.8 & 278.1 & 295.9 \\
EXP4 & 54.8 & 47.9 & 38.2 & -6.2 & 179.5 & 185.7 \\
EXP3b & 54.6 & 41.2 & 44.5 & -8.7 & 174.5 & 183.2 \\
EXP5 & 42.9 & 28.0 & 38.0 & -9.3 & 110.0 & 119.3 \\
\hline
\end{tabular}


Table 19. LHF $\left(\mathrm{W} \mathrm{m}^{-2}\right)$ simulated by UTOPIA and NOAH, initialized with GLDAS, at the CO station.

\begin{tabular}{ccccccc}
\hline & Mean & Standard Deviation & Median & Min & Max & Range \\
\hline EXP2b & 48.6 & 55.0 & 32.4 & -21.9 & 281.3 & 303.2 \\
EXP4 & 64.3 & 60.2 & 45.2 & -7.0 & 200.4 & 207.4 \\
EXP3b & 58.2 & 45.0 & 50.2 & -27.0 & 187.9 & 214.9 \\
EXP5 & 46.7 & 30.7 & 39.7 & -3.3 & 130.4 & 133.7 \\
\hline
\end{tabular}

Table 20. LHF $\left(\mathrm{W} \mathrm{m}^{-2}\right)$ simulated by UTOPIA and NOAH, initialized with GLDAS, at the FB station.

\begin{tabular}{ccccccc}
\hline & Mean & Standard Deviation & Median & Min & Max & Range \\
\hline EXP2b & 54.1 & 57.2 & 37.3 & -20.6 & 296.0 & 316.6 \\
EXP4 & 62.3 & 56.1 & 44.2 & -4.0 & 209.5 & 213.5 \\
EXP3b & 54.1 & 41.6 & 45.0 & -23.4 & 186.6 & 210.0 \\
EXP5 & 57.0 & 37.9 & 50.3 & -5.6 & 159.1 & 164.7 \\
\hline
\end{tabular}

\subsubsection{Soil Temperature (TS)}

ST shows (Tables 21-23 and Supplementary Figures S18-S20) differences in the range of $1-4{ }^{\circ} \mathrm{C}$ for mean and median values and $1-5^{\circ} \mathrm{C}$ for extremes, with UTOPIA generally warmer than NOAH, and also $1-3{ }^{\circ} \mathrm{C}$ for the range, with UTOPIA showing the largest. A difference exists between the two different boundary conditions: while the two models almost conserve their departure from each other, the GLDAS-2.1 initialization produces the coldest minima for NOAH, and these are the coldest values, while the GLDAS-2.0 produces minima compatible between the two models. Maxima and ranges are lower in EXP2b and EXP5, e.g., those initialized with GLDAS-2.0, while mean and median values are slightly larger. Considering also what we said in analyzing Tables 9 and 10, we can conclude that GLDAS initialization seems not influencing too much soil temperature, as well as the vegetation type, and that UTOPIA values, whose minima are lower than those of NOAH, seem more compatible with the data. A possible reason for this behavior may consist in the special scheme used by UTOPIA to represent the phenomenon of freezing water in the soil with negative temperatures [22].

Table 21. TS $\left({ }^{\circ} \mathrm{C}\right)(0-10 \mathrm{~cm})$ simulated by UTOPIA and NOAH, initialized with GLDAS, at the CF station.

\begin{tabular}{ccccccc}
\hline & Mean & Standard Deviation & Median & Min & Max & Range \\
\hline EXP2b & 13.2 & 8.8 & 13.5 & -2.9 & 29.9 & 32.8 \\
EXP4 & 11.3 & 8.5 & 11.2 & -4.4 & 27.5 & 31.9 \\
EXP3b & 14.9 & 7.2 & 15.3 & -1.3 & 27.9 & 29.2 \\
EXP5 & 14.2 & 7.0 & 14.2 & -1.7 & 26.5 & 28.2 \\
\hline
\end{tabular}

Table 22. TS $\left({ }^{\circ} \mathrm{C}\right)(0-10 \mathrm{~cm})$ simulated by UTOPIA and NOAH, initialized with GLDAS, at the CO station.

\begin{tabular}{ccccccc}
\hline & Mean & Standard Deviation & Median & Min & Max & Range \\
\hline EXP2b & 12.2 & 8.5 & 11.9 & -2.9 & 28.6 & 31.5 \\
EXP4 & 10.0 & 8.3 & 10.5 & -5.2 & 24.9 & 30.1 \\
EXP3b & 14.5 & 7.4 & 15.4 & -2.0 & 27.5 & 29.5 \\
EXP5 & 12.7 & 6.7 & 12.8 & -1.6 & 24.4 & 26.0 \\
\hline
\end{tabular}

Table 23. TS $\left({ }^{\circ} \mathrm{C}\right)(0-10 \mathrm{~cm})$ simulated by UTOPIA and NOAH, initialized with GLDAS, at the FU station.

\begin{tabular}{ccccccc}
\hline & Mean & Standard Deviation & Median & Min & Max & Range \\
\hline EXP2b & 13.5 & 8.7 & 13.6 & -2.6 & 30.0 & 32.6 \\
EXP4 & 11.8 & 8.3 & 11.9 & -3.4 & 27.7 & 31.1 \\
EXP3b & 14.5 & 7.5 & 15.3 & -1.7 & 27.7 & 29.4 \\
EXP5 & 13.3 & 6.8 & 13.3 & -1.4 & 24.9 & 26.3 \\
\hline
\end{tabular}




\subsubsection{Soil Moisture (VWC)}

VWC (soil moisture) shows (Tables 24-26 and Supplementary Figures S21-S23) the largest variations among models and boundary conditions, FB being the site in which mean and median values almost equal between each other. NOAH extremes in EXP4 exceed those of UTOPIA in EXP2b, with lower minima and higher maxima. UTOPIA distribution of values is similar among EXP2b and EXP3b, while for NOAH difference in distribution between EXP4 and EXP5 are quite large in CF (mean values in EXP5 much larger than in EXP4) and CO (mean values in EXP5 much smaller than in EXP4), and more reasonable in FU (EXP4 ranges being anyway larger than those of EXP5). However, also in this site, the NOAH range was much larger than UTOPIA one. Remembering that, in EXP1,2,3a (Table 11), UTOPIA was able to reproduce VWC maxima but overestimated the minima, in EXP4,5 we can notice that the NOAH minima, being lower than those of UTOPIA, may be more realistic, but the NOAH maxima, being larger than those of UTOPIA, may be more unrealistic. Regarding the version of GLDAS, GLDAS2.1 seems able to allow the calculation of more realistic values, if compared with GLDAS2.0.

Table 24. VWC $\left(\mathrm{m}^{3} \mathrm{~m}^{-3}\right)(0-10 \mathrm{~cm})$ simulated by UTOPIA and NOAH, initialized with GLDAS, at the CF station.

\begin{tabular}{ccccccc}
\hline & Mean & Standard Deviation & Median & Min & Max & Range \\
\hline EXP2b & 0.230 & 0.050 & 0.250 & 0.150 & 0.330 & 0.180 \\
EXP4 & 0.270 & 0.080 & 0.270 & 0.110 & 0.440 & 0.330 \\
EXP3b & 0.250 & 0.060 & 0.270 & 0.150 & 0.350 & 0.200 \\
EXP5 & 0.350 & 0.020 & 0.350 & 0.280 & 0.430 & 0.150 \\
\hline
\end{tabular}

Table 25. VWC $\left(\mathrm{m}^{3} \mathrm{~m}^{-3}\right)(0-10 \mathrm{~cm})$ simulated by UTOPIA and NOAH, initialized with GLDAS, at the CO station.

\begin{tabular}{ccccccc}
\hline & Mean & Standard Deviation & Median & Min & Max & Range \\
\hline EXP2b & 0.32 & 0.04 & 0.33 & 0.23 & 0.41 & 0.18 \\
EXP4 & 0.36 & 0.06 & 0.36 & 0.19 & 0.47 & 0.28 \\
EXP3b & 0.33 & 0.04 & 0.35 & 0.25 & 0.41 & 0.16 \\
EXP5 & 0.28 & 0.04 & 0.29 & 0.16 & 0.38 & 0.22 \\
\hline
\end{tabular}

Table 26. VWC $\left(\mathrm{m}^{3} \mathrm{~m}^{-3}\right)(0-10 \mathrm{~cm})$ simulated by UTOPIA and NOAH, initialized with GLDAS, at the FB station.

\begin{tabular}{ccccccc}
\hline & Mean & Standard Deviation & Median & Min & Max & Range \\
\hline EXP2b & 0.32 & 0.05 & 0.34 & 0.25 & 0.40 & 0.15 \\
EXP4 & 0.33 & 0.07 & 0.34 & 0.15 & 0.47 & 0.32 \\
EXP3b & 0.33 & 0.04 & 0.34 & 0.25 & 0.41 & 0.16 \\
EXP5 & 0.33 & 0.04 & 0.34 & 0.19 & 0.43 & 0.24 \\
\hline
\end{tabular}

\section{Discussion}

\subsection{UTOPIA Simulations Compared with the Observations}

The comparison between simulated and observed data shows several different results. Each of the analyzed variables performs better in one of the experiments, which is not the same of other variables.

We expected that the use of measurements carried out "in situ", and more precisely within the vineyards (EXP1), could produce model outputs closer to the observations than the use of data coming from the GLDAS database, in which each grid point represents an average area of about $225 \mathrm{~km}^{2}$, with smoother topography and microclimate. In effects, even if a general conclusion appears not easy to be derived, generally the simulations belonging to EXP1 give overall the best result, and the differences can be regarded as the typical expected errors when a model instead of observations is used. 
When GLDAS is used for the boundary conditions, the differences with respect to the observations generally increase, still remaining in the range of instrumental errors for most variables. An inspection on the input values given to the LSMs UTOPIA and NOAH (see Tables S1-S18) reveals that the differences between the two databases appear not small and not negligible, and that generally the data of GLDAS2.1 appear closer to the measurements than those of GLDAS2.0. Thus, it is not surprising that, between GLDAS-2.1 and GLDAS-2.0, the former gives generally better performances with respect to the latter.

The most critical variables to be simulated are the maxima of soil temperatures and the minima of soil moistures. Regarding the latter, a possible explanation is the tendency, in the GLDAS databases, to overestimate the amount of precipitation, while for the soil temperature we think that a possible reason is the combined effect of higher air temperature and solar radiation.

Regarding the simulations of energy fluxes, UTOPIA well reproduces SHF, LHF and RNET when the used boundary conditions are the vineyard observations and the selected vegetation type is "vineyard" for SHF at CF and CO stations, and LHF at FB station, and with "irrigated crop" for RNET at the $\mathrm{CO}$ station.

At the FB station, the simulations performed using the vineyard dataset as boundary conditions also overestimate the observed values for SHF and TS. We are unable, at this stage, to understand why this departures are present, however, we think that these values could be considered as a sort of maximum error when a model such as UTOPIA is used. The fact that UTOPIA and NOAH outputs in this site are also quite similar may lead us to think that perhaps the quality of the data used for the reconstruction of the Fubine dataset may be a concomitant cause.

Note that vegetation parameters are: albedo for short- and long-wave radiation, height of the vegetation and its root length, the Noilhan coefficient, the inverse square root of leaf dimension, the seasonal variation and the maximum value of vegetation cover, the maximum value of LAI and its yearly excursion, and some coefficients used in photosynthesis evaluation. According to our previous experience in using UTOPIA, the most important parameters that affect net radiation and turbulent heat fluxes are the albedo for the net radiation, and the LAI and the vegetation cover for the fluxes.

Comparison of simulated and measured energy balance fluxes has been also done in [55] in three experimental sites, hourly values of fluxes have been compared obtaining good model performances, but the results also showed that the effects of topography on energy balance were significant even on moderate slopes, and this aspect could also be true for our experimental sites. In particular, this may be true considering the simulations performed with forcing given by observations versus GLDAS.

Latent heat fluxes have also been analyzed in [2] over forest sites, showing that LHF exhibited distinct seasonal changes and that the modeled values resulted to be overestimated before the initiation of the growing season. Also, UTOPIA LHF values exhibit an overestimation of maxima for all the different boundary conditions. Regarding the mean values, they are overestimated, except for the experiment EXP1b.

The results of simulations of temperature of upper soil layer differ from those of the other variables. The experiments EXP1a/b (boundary conditions: vineyard observations) give, in particular, minima and maxima quite different from observations: minima were slightly underestimated, and maxima were widely overestimated. Since the range of simulations driven by GLDAS2.0 is usually lower for all variables, if compared with those driven by GLDAS2.1, this variable is the only case in which the outputs of UTOPIA driven by GLDAS2.0 are closer to observations than those of GLDAS2.1.

Measurements of soil water content were performed only in CO site, and minimum observed value was rather low $\left(0.09 \mathrm{~m}^{3}{ }_{\text {water }} \mathrm{m}^{-3}\right.$ soil $)$, whereas maxima were similar to those simulated. Simulations of all experiments overestimated mean values and minima.

For deep soil layers, UTOPIA minima were fixed, in all simulations, at the values of the wilting point for the considered soil (respectively $0.155 \mathrm{~m}^{3}$ water $\mathrm{m}^{-3}$ soil for loam soil, $0.250 \mathrm{~m}^{3} \mathrm{~m}^{-3}$ soil for clay loam soil, 0.1794 for silty loam soil and 0.2181 for silty clay loam soil). When soil moisture is lower than the wilting point in the root layer, transpiration is not effective, and gravitational drainage is 
negligible, as it depends from soil moisture with a power law [37]. The only process able to extract moisture from this soil layer is thus the evaporation from the surface, that depends on the moisture itself (the resistance increases with low moistures). Thus, it is quite difficult to extract water from a soil in which the VWC is below the wilting point, and for this reason the soil moisture may remain constant. This is what happens in UTOPIA simulations, while in the case of NOAH model, there are some additional mechanisms allowing to extract water from a soil below the wilting point threshold. The observations carried out at CO site show some values which are quite small, well below the wilting point threshold for that particular soil type, this behavior seems in contrast with the physical process of water removal from soil by transpiration. We can hypothesize that the concept of fixed wilting point for a given soil type may be wrong since some plants (present between the vineyards) may have a lower wilting point with respect to vineyards, and this effect could eventually explain the VWC lowering in such a dry environment.

\subsection{Intercomparison between UTOPIA and NOAH Simulations Initialized with GLDAS}

The intercomparison between the two land surface models UTOPIA and NOAH has been performed in the experiments EXP2b and EXP3b for UTOPIA, and EXP4 and EXP5 for NOAH. The only vegetation type considered here was 'irrigated $\mathrm{crop}^{\prime}$, and the analyzed period time was three years because the comparison involved only simulated data and not field observations. Note that UTOPIA and NOAH have been driven by the same dataset in each experiment, thus eventual differences can be attributed to the respective model parameterizations.

In all experiments, the RNET mean values simulated by UTOPIA were lower than those of NOAH. All initial and boundary conditions being equal for the models, the difference can be attributed to the soil surface temperature, larger for UTOPIA, which means a larger infrared upward flux and then a lower net radiation.

The comparison of SHF and LHF mean values did not show a definite conclusion, because values vary with experiment and location not uniformly. The heat fluxes from NOAH model have been analyzed and compared with products of different land-surface models, reanalysis and satellite-based products [41]. Noah model latent heat flux correlates well with CLM and Mosaic model fluxes regarding the monthly means. Regarding the annual means of LHF, SHF and RNET, the NOAH model had values similar to the CLM model.

The analysis of soil temperatures shows that mean values simulated by the UTOPIA model were larger than those of the NOAH model in all experiments, and minima and maxima were also larger. The reason can be, being that the boundary conditions were the same for both models, a different parameterization of the processes involved in the calculation of different soil layers temperatures, or an imprecision in the determination of the energy budget, which influences the soil heat flux and hence the soil temperature. At this purpose, we can remember that the UTOPIA model consider nine soil layers, whereas the NOAH model only considers four, and that UTOPIA parameterizes the soil freezing.

Also, the results of volumetric water content simulations did not show a clear behavior: mean values were very different, depending on site and experiment, except for the FB station, where mean values were coincident (but ranges were very different). The largest differences between the two models were in the extremes: minima were lower for NOAH and maxima were higher for UTOPIA, while mean values did not show a unique behavior. These differences could have some impacts in the evaluation of photosynthetic processes, vegetation resistance, hydrological budget, and carbon assimilation. Unfortunately, this study is unable to give a definite answer about which model gives the best performance about this variable, nor justify why this behavior is present, perhaps further observations are required. We can just remember here that GLDAS databases overestimate the precipitation in all sites, and that VWC minima of UTOPIA over vineyards were overestimated (but not the corresponding maxima), perhaps due to the presence of some grasses within the vineyards, not considered by the model. 


\section{Conclusions}

This paper described a study performed by analyzing the simulations of some variables referred to the surface boundary layer in a vineyard environment, using suitable models able to process the micro-meteorological conditions and exchanges processes at the atmosphere/biosphere interface. Two models were used: The Land Surface Model UTOPIA (University of Torino model for land Process Interaction with Atmosphere), and the NOAH model. We performed the simulations with UTOPIA, while for NOAH we retrieved its data from the GLDAS2.1 and GLDAS2.0 databases. The selected areas were located in the Piemonte (Piedmont) region, NW Italy, which is characterized by the presence of many vineyards. In particular, the forcing data used in the input for UTOPIA came from an experimental campaign carried out during the 2008, 2009, and 2010 vegetative seasons in three Piedmontese vineyards. Additional simulations were performed using the meteorological data gathered from the freely available global database, GLDAS (version 2.0 and 2.1): the same data were used by the GLDAS team to perform the NOAH simulations. The results of simulations allow us to evaluate the daily values of the following variables: turbulent heat fluxes (sensible and latent), temperature and humidity of the soil. The UTOPIA output driven by observations within the vineyard were compared with the measurements carried out in the experimental campaign. The results showed that energy budget components on a daily basis generally agree with observations, with average overor under-estimations comparable with the errors in the evaluations of such variables. Regarding soil variables, UTOPIA exaggerates the annual variations of temperature and predicts too-large soil moisture. Subsequently, the UTOPIA simulations driven by GLDAS were compared with the one driven by observations. The results of this comparison showed that, when GLDAS2.1 input were used, the quality of UTOPIA outputs was slightly worsened, with the deviations still remaining within the range of the experimental measurement errors. On the contrary, when GLDAS2.0 input were used, the outputs presented larger deviations with respect to outputs from UTOPIA driven by observations, almost for every variable, with the deviations often being beyond the measurement errors.

Finally, the UTOPIA simulations driven by GLDAS were compared with the outputs of the NOAH model: in this case, UTOPIA soil and vegetation was initialized as for the NOAH simulations, in order to have the same initial configuration for both models. The results of this comparison showed that the two models can be considered more or less equivalent, with average differences among them comprised within the range of the measurement errors. However, for soil variables, the largest differences between the models appear in the extremes. Since NOAH minima of VWC (maxima of TS) appear to be too low (high) considering the physical processes acting on temperatures and moistures, such as the limitation to evapotranspiration due to dry soil, and the limitation of soil cooling due to the water freezing, perhaps we may conclude that UTOPIA values for soil variables appear slightly more realistic.

Supplementary Materials: The following are available online at http://www.mdpi.com/2076-3417/9/18/3880/s1, Sections S1-S4: statistics of the input data used for the UTOPIA simulations, statistics of the simulations expressed in form of violin plots, time series of a term of simulated and observed soil temperatures, and correlation coefficients between observed and simulated data in experiments EXP1-3.

Author Contributions: V.A. and C.C. have contributed in equal measure to the research article.

Funding: This research was partially funded by "MACSUR-Modelling European Agriculture for Food Security with Climate Change, a FACCE JPI knowledge hub" funded for the Italian partnership by the Italian Ministry of Agricultural Food and Forestry Policies (D.M. 24064/7303/15). The Lagrange Project-CRT Foundation/Isi Foundation and IWAY s.r.l. supported two grants of one year for developing the project.

Acknowledgments: We acknowledge Massimiliano Manfrin, and Davide Bertoni for the help in managing data and implementing computers and software, Silvia Ferrarese for the fruitful discussions, and Hualan Rui for the help in managing the GLDAS dataset. We acknowledge also the scientific team that made available for research purposes the dataset GLDAS in both versions.

Conflicts of Interest: The authors declare no conflict of interest. 


\section{Appendix A}

\section{Method Used for the Interpolation of Data Observed in Vineyards}

Measurements in the three experimental sites CF (Castiglione Falletto), $\mathrm{CO}$ (Cocconato), and FB (Fubine) were mainly carried out during the three vegetative seasons from 2008 to 2010, even if most instruments remained active throughout that time. To run simulations with the UTOPIA, to eliminate the spin-up problem, we decided to start all simulations one year earlier, disregarding the first year, thus the complete data period needed was of four years, e.g., 2007-2010. In order to have in this 4-year period the complete dataset of variables needed by UTOPIA (temperature, humidity, pressure, precipitation, horizontal wind speed components, and solar radiation), some interpolation procedures were performed, using the data of the available neighbor meteorological stations coming from the regional meteorological and agrometeorological networks. For some data, such as pressure and precipitation (and, for $\mathrm{CF}$, also humidity), measurements within vineyards were unavailable, thus the reconstruction was performed on the basis of the data of neighboring stations, using as weight the inverse square distance among the station and the vineyard. For humidity, data were converted in dew-point temperatures before interpolation, and then reconverted into relative humidity after. For precipitation, the data were converted in rates. For all other variables, the regression between daily mean data recorded at the experimental sites and those measured in all neighbor stations was firstly performed. Subsequently, an interpolation was performed on half hourly data, using as weights the fourth power of the correlation coefficients evaluated for daily mean values. For air temperature, it was investigated if, using separate regressions for minimum and maximum temperatures (and then weighting the instantaneous value with the difference between minimum and maximum temperatures), the quality of interpolated data was improving. Since the result was not positive, the method was not used. The comparison between the data reconstructed with this method and those measured in the experimental sites [30-32] (Table A1) revealed a good agreement for all variables. The errors were larger considering daily extreme values (minima and maxima), their average remaining under the uncertainty of the instrument.

Table A1. Root mean square error for daily mean values of UTOPIA inputs interpolated in the three vineyards, compared with available observations.

\begin{tabular}{ccccc}
\hline Station/Variable & Temperature $\left({ }^{\circ} \mathbf{C}\right)$ & Dew Point $\left({ }^{\circ} \mathbf{C}\right)$ & Radiation $\left(\mathbf{W ~ m}^{-\mathbf{2}}\right)$ & Wind Speed $\left(\mathbf{m ~ s}^{-\mathbf{1}}\right)$ \\
\hline Castiglion Falletto & 0.02 & - & -3 & 0.01 \\
Cocconato & 0.03 & 0.09 & -1 & 0.01 \\
Fubine & 0.02 & 0.22 & -7 & 0.01 \\
\hline
\end{tabular}

Despite the fact that some variables (such as pressure and precipitation) were entirely reconstructed using neighbor stations, we think that the dataset created with this method can be considered as the closest possible group of complete data, close to the observations, to drive UTOPIA. In the paper, these data will be hereafter referred to as "observations".

\section{References}

1. Park, S.; Park, S.K. Parameterization of the snow-covered surface albedo in the Noah-MP Version 1.0 by implementing vegetation effects. Geosci. Model. Dev. 2016, 9, 1073-1085. [CrossRef]

2. Gim, H.-J; Park, S.K.; Kang, M.; Thakuri, B.M.; Kim, J.; Ho, C.-H. An improved parameterization of the allocation of assimilated carbon to plant parts in vegetation dynamics for Noah-MP. J. Adv. Model. Earth Syst. 2017, 9, 1776-1794. [CrossRef]

3. Becklin, K.M.; Anderson, J.T.; Gerhart, L.M.; Wadgymar, S.M.; Wessinger, C.A.; Ward, J.K. Examining Plant Physiological Responses to Climate Change through an Evolutionary Lens. Plant. Physiol 2016, 172, 635-649. [CrossRef] [PubMed] 
4. Shanmuganthan, S.; Ghobakhlou, A.; Allis, P. Sensors for modeling the effects of climate change on grapevine growth and wine quality. In Proceedings of the 12nd WSEAS International Conference on CIRCUITS, World Scientific and Engineering Academy and Society, Heraklion, Greece, 23-25 July 2008; pp. 315-320.

5. Francone, C.; Cassardo, C.; Spanna, F.; Alemanno, L.; Bertoni, D.; Richiardone, R.; Vercellino, I. Preliminary Results on the Evaluation of Factors Infuencing Evapotranspiration Processes in Vineyards. Water 2010, 2, 916-937. [CrossRef]

6. Downey, M.O.; Dokoozlian, N.K.; Krstic, M.P. Cultural practice and environmental impacts on the flavonoid composition of grapes and wine: A review of recent research. Am. J. Enol. Vitic 2006, 57, 257-268.

7. Joscelyne, V.L.; Downey, M.O.; Mazza, M.; Bastian, S. Partial Shading of Cabernet Sauvignon and Shiraz Vines Altered Wine Color and Mouthfeel Attributes, but Increased Exposure Had Little Impact. J. Agric. Food Chem. 2007, 55, 10888-10896. [CrossRef] [PubMed]

8. Ristic, R.; Downey, M.O.; Iland, P.G.; Bindon, K.; Francis, I.L.; Herderich, M.; Robinson, S.P. Exclusion of sunlight from Shiraz grapes alters wine colour, tannin and sensory properties. Aust. J. Grape Wine Res. 2007, 13, 53-65. [CrossRef]

9. Cohen, S.D.; Tarara, J.M.; Kennedy, J.A. Assessing the impact of temperature on grape phenolic metabolism. Anal. Chim. Acta 2008, 621, 57-67. [CrossRef] [PubMed]

10. Chalmers, Y.M.; Downey, M.O.; Krstic, M.P.; Loveys, B.R.; Dry, P.R. Influence of sustained deficit irrigation on colour parameters of Cabernet Sauvignon and Shiraz microscale wine fermentations. Aust. J. Grape Wine Res. 2010, 16, 301-313. [CrossRef]

11. Chorti, E.; Guidoni, S.; Ferrandino, A.; Novello, V. Effect of different cluster sunlight exposure levels on ripening and anthocyanin accumulation in Nebbiolo grapes. Am. J. Enol. Vitic. 2010, 61, 23-30.

12. Martinez de Toda, F.; Sancha, J.C.; Balda, P. Reducing the Sugar and pH of the Grape (Vitis vinifera L. cvs. "Grenache" and 'tempranillo') Through a Single Shoot trimming. S. Afr. J. Enol. Vitic. 2013, 34, $246-251$.

13. Heilman, J.L.; McInnes, K.J.; Savage, M.J.; Gesch, R.W.; Lascano, R.J. Soil and canopy energy balance in a west Texas vineyard. Agric. For. Meteorol. 1994, 71, 99-114. [CrossRef]

14. Sturman, A.; Schulmann, T.; Soltanzadeh, I.; Gendig, E.; Zawar-Reza, P.; Katurji, M.; Parker, A.; Trought, M.; Agnew, R. Application of high-resolution climate measurement and modelling to the adaptation of New Zealand vineyard regions to climate variability. Oeno One 2017, 51, 99-105. [CrossRef]

15. Brisson, N.; Mary, B.; Ripoche, D.; Jeuffroy, M.H.; Ruget, F.; Nicoullaud, B.; Gate, P.; Devienne-Barret, F.; Antonioletti, R.; Durr, C.; et al. STICS: A generic model for the simulation of crops and their water and nitrogen balances. I. Theory and parameterization applied to wheat and corn. Agronomie 1998, 18, 311-346. [CrossRef]

16. Brisson, N.; Gary, C.; Justes, E.; Roche, R.; Mary, B.; Ripoche, D.; Zimmer, D.; Sierra, J.; Bertuzzi, P.; Burger, P.; et al. An overview of the crop model STICS. Eur. J. Agron. 2003, 18, 309-332. [CrossRef]

17. Poni, S.; Palliotti, A.; Bernizzoni, F. Calibration and Evaluation of a $S^{\mathrm{TEL}}$ LA Software-based Daily CO2 Balance Model in Vitis Vinifera L. J. Am. Soc. Hort. Sci. 2006, 131, 273-283. [CrossRef]

18. Manabe, S. Climate and the ocean circulation: The atmospheric circulation and the hydrology of the Earth's surface. Mon. Weather Rev. 1969, 97, 739-805. [CrossRef]

19. Deardorff, J.W. Efficient prediction of ground surface temperature and moisture with inclusion of a layer of vegetation. J. Geophys. Res. 1978, 83, 1889-1903. [CrossRef]

20. Dickinson, R.E.; Henderson-Sellers, A.; Kennedy, P.J.; Wilson, M.F. Biosphere Atmosphere Transfer Scheme (BATS) for the NCAR Community Climate Model; NCAR: Boulder, CO, USA, 1986.

21. Sellers, P.J.; Mintz, Y. A simple biosphere model (SiB) for use within general circulation models. J. Atmos. Sci. 1986, 43, 505-531. [CrossRef]

22. Cassardo, C. The University of Torino Model of Land Process Interaction with Atmosphere (UTOPIA) Version 2015; Technical Report No. SSRC/CCCPR-TR-2015-1; Ewha Womans University: Seoul, Korea, 2015; p. 80.

23. Andreoli, V.; Cassardo, C.; La Iacona, T.; Spanna, F. Description and preliminary simulations with thenumerical model Italian Vineyard Integrated Numerical model for Estimating physiological values (IVINE). Agronomy 2019, 9, 94. [CrossRef]

24. Rossi, V.; Salinari, F.; Poni, S.; Caffi, T.; Bettati, T. Addressing the implementation problem in agricultural decision support systems: The example of vite.net. Comput. Electron. Agric. 2014, 2014, 88-99. [CrossRef]

25. Pitman, A.J. Review: The evolution of, and revolution in, land surface schemes designed for climate models. Int. J. Clim. 2003, 23, 479-510. [CrossRef] 
26. Francone, C.; Cassardo, C.; Richiardone, R.; Confalonieri, R. Sensitivity Analysis and investigation of the behaviour of the UTOPIA land surface process model: A case study for vineyards in northern Italy. Bound. Layer Meteorol. 2012, 144, 419-430. [CrossRef]

27. Andreoli, V.; Bertoni, D.; Cassardo, C.; Ferrarese, S.; Francone, C.; Spanna, F. Analysis of micrometeorological conditions in Piedmontese vineyards. Ital. J. Agrometeorol. 2018, 2018, 27-40. [CrossRef]

28. Cassardo, C.; Sacchetti, D.; Morselli, M.G.; Anfossi, D.; Brusasca, G.; Longhetto, A. A Study of the Assessment of Air Temperature, and Sensible-and Latent-Heat Fluxes from Sonic-Anemometer Observations. Il Nuovo Cim. 1995, 18, 419-440. [CrossRef]

29. Richiardone, R.; Giampiccolo, R.; Ferrarese, S.; Manfrin, M. Detection of flow distortion and system errors in sonic anemometry using the planar fit method. Bound. Layer Meteorol. 2008, 128, 277-302. [CrossRef]

30. Rossetti, S. Studio del Microclima di Alcuni Vigneti Piemontesi. Master's Thesis, University of Torino, Torino, Italy, 2011.

31. Andreoli, V.; Cassardo, C.; Spanna, F. Micrometeorological conditions in Piedmontese vineyards. In Agrometeorology to Feed the Planet: Water; Ventura, F., Pieri, L., Eds.; Fondazione Edmund Mach: San Michele all'Adige, Italy, 2015; pp. 52-53.

32. Andreoli, V.; Cassardo, C.; Spanna, F. Radiation measurements in Piedmontese vineyards. In Agrometeorology to Feed the Planet: Water; Ventura, F., Pieri, L., Eds.; Fondazione Edmund Mach: San Michele all'Adige, Italy, 2015; pp. 54-55.

33. Bahrami, A. Climatic and Micrometeorological Analysis of Some Piedmontese Vineyards. Master's Thesis, University of Torino, Torino, Italy, 2016. APRIL 2016.

34. Lazzarato, F. Ricostruzione di Parametri Utili a Definire il Microclima dei Vigneti Piemontesi Mediante Simulazioni. Master's Thesis, University of Torino, Torino, Italy, 2017. APRIL 2017.

35. Cassardo, C.; Ji, J.; Longhetto, A. A study of the performance of a land surface process model (LSPM). Bound. Layer Meteorol. 1995, 3, 87-121. [CrossRef]

36. Cassardo, C. The Land Surface Process Model (LSPM) Version 2006, The Complete Manual; Internal Report No. DFG 1/2006; Department of General Physics “A. Avogadro", University of Torino: Torino, Italy, 2006.

37. Clapp, R.B.; Hornberger, G.M. Empirical Equations for Some Soil Hydraulic Properties. Water Resour. Res. 1978, 14, 601-604. [CrossRef]

38. US Department of Agriculture. Soil Mechanics Level I. Module 3. USDA Textural Classification Study Guide. US Department of Agriculture; 1987. Available online: https://www.wcc.nrcs.usda.gov/ftpref/wntsc/H\&H/ training/soilsOther/soil-USDA-textural-class.pdf (accessed on 12 September 2019).

39. Burt, R. (Ed.) Soil Survey Investigations Report No. 45, 2011, Lincoln, Nebraska. Available online: https: //www.nrcs.usda.gov/Internet/FSE_DOCUMENTS/stelprdb1253871.pdf (accessed on 12 September 2019).

40. Mahrt, L.; Pan, H. A two-layer model for soil hydrology. Bound. Layer Meteorol. 1984, 29, 1-20. [CrossRef]

41. Jimenez, C.; Prigent, C.; Mueller, B.; Seneviratne, S.I.; McCabe, M.F.; Wood, E.F.; Rossow, W.B.; Balsamo, G.; Betts, A.K.; Dirmeyer, P.A.; et al. Global inter-comparison of 12 land surface heat flux estimates. J. Geophys. Res. 2011, 116, D02102. [CrossRef]

42. Rodell, M.; Houser, P.R.; Jambor, U.; Gottschalck, J.; Mitchell, K.; Meng, C.-J.; Arsenault, K.; Cosgrove, B.; Radakovich, J.; Bosilovich, M.; et al. The Global Land Data Assimilation System. Bull. Am. Meteorol. Soc. 2004, 85, 381-394. [CrossRef]

43. Rui, H.; Beaudoing, H. Readme Document for GLDAS Version 1 Data Products; National Aeronautics and Space Administration Goddard Earth Science Data Information Center (GES DISC): Greenbelt, MD, USA, 2017.

44. Rui, H.; Beaudoing, H. Readme Document for GLDAS Version 2 Data Products; National Aeronautics and Space Administration Goddard Earth Science Data Information Center (GES DISC): Greenbelt, MD, USA, 2017.

45. Rui, H.; Beaudoing, H. README Document for NASA GLDAS Version 2 Data Products; Goddart Earth Sciences Data and Information Services Center (GES DISC): Greenbelt, MD, USA, 2018.

46. Sheffield, J.; Goteti, G.; Wood, E.F. Development of a 50-yr high resolution global dataset of meteorological forcing for land surface modelling. J. Clim. 2006, 19, 3088-3111. [CrossRef]

47. Derber, J.C.; Parrish, D.F.; Lord, S.J. The new global operational analysis system at the National Meteorological Center. Weather Forecast. 1991, 6, 538-547. [CrossRef]

48. Adler, R.F.; Huffman, G.J.; Chang, A.; Ferraro, R.; Xie, P.P.; Janowiak, J.; Rudolph, B.; Schneider, U.; Curtis, S.; Bolvin, D.; et al. The Version-2 Global Precipitation Climatology Project (GPCP) Monthly Precipation Analysis (1979-Present). J. Hydrometeorol. 2003, 4, 1147-1167. [CrossRef] 
49. Wang, W.; Cui, W.; Wang, X.; Chen, X. Evaluation of GLDAS-1 and GLDAS-2 Forcing Data and Noah Model Simulations over China at the Monthly Scale. J. Hydrometeorol. 2016, 17, 2815-2833. [CrossRef]

50. Qi, W.; Zhang, C.; Fu, G.; Zhou, H. Global Land Data Assimilation System data assessment using a distributed biosphere hydrological model. J. Hydrol. 2015, 528, 652-667. [CrossRef]

51. Zaitchik, B.; Rodell, M.; Olivera, F. Evaluation of the Global Land Data Assimilation System using global river discharge data and source-to-sink routing scheme. Water Resour. Res. 2010, 46. [CrossRef]

52. Chen, Y.; Yang, K.; Qin, J.; Zhao, L.; Tang, W.; Han, M. Evaluation of AMSR-E retrievals and GLDAS simulations against observations of soil moisture network on the central Tibetan Plateau. J. Geophys. Res. Atmos. 2013, 118, 4466-4475. [CrossRef]

53. Mauder, M.; Zeeman, M.J. Field intercomparison of prevailing sonic anemometers. Atmos. Meas. Tech. 2018, 11, 249-263. [CrossRef]

54. Van Der Molen, M.K.; Gash, J.H.C.; Elbers, J.A. Sonic Anemometer (co)sine response and flux measurement II. The effect of introducing an angle of attack dependent calibration. Agric. Forest Meteorol. 2004, 122, 95-109. [CrossRef]

55. Rana, G.; Ferrara, R.M.; Martinelli, N.; Personnic, P.; Cellier, P.M. Estimating enery fluxes from sloping crops using standard agrometeorological measurements and topography. Agric. For. Meteorol. 2007, 147, 116-133. [CrossRef]

(C) 2019 by the authors. Licensee MDPI, Basel, Switzerland. This article is an open access article distributed under the terms and conditions of the Creative Commons Attribution (CC BY) license (http://creativecommons.org/licenses/by/4.0/). 